\title{
Deliberative multi-actor dialogues as opportunities for transformative social learning and conflict resolution in international environmental negotiations
}

\author{
Maria Schultz ${ }^{1}$ (D) $\cdot$ Thomas Hahn $^{1}$ (D) $\cdot$ Claudia Ituarte-Lima $^{1}$ (D) $\cdot$ Niclas Hällström $^{2}$
}

Accepted: 17 August 2018 / Published online: 27 August 2018

(c) The Author(s) 2018

\begin{abstract}
The format for formal international negotiations on environment and development sometimes prevents negotiators from truly listening to each other and adapt pre-existing positions to realize constructive conflict resolution. In this paper we present and analyse "MultiActor Dialogue Seminars" (MADS) as an approach to contribute to transformative social learning and conflict resolution, and the contribution to tangible and intangible outcomes in formal negotiations. Unlike negotiations, the objective of MADS is not to agree on a text, but to identify areas of agreement and disagreement, build trust and understanding and identify policy options that are tailored to different cultural-political and value systems. As a case study we use the breakdown of the negotiations at the formal Convention on Biological Diversity (CBD) Conference in 2010 regarding "innovative financial mechanisms," and subsequent two international Quito Dialogues using the MADS approach. Through a composite of methods this article reveals the effects of the Quito Dialogues on formal CBD negotiations. The Quito Dialogues contributed to bringing actors out of their deadlock and thereby paving the way for constructive results in the formal CBD negotiations, evident by references in CBD Decisions adopted by 196 CBD Parties. We discuss key design and implementation factors which were decisive for these effects including the importance of a bridging organization, trust building, exploration of both convergences and divergences, involvement of participants with diverse and conflicting views early in the planning, promotion of active listening and addressing diverse knowledge systems and power asymmetries.
\end{abstract}

Keywords Multi-Actor Dialogue Seminars · Transformative learning · Convention on Biological Diversity · Biodiversity financing mechanisms · Adaptive governance · Transformative governance $\cdot$ SwedBio

Electronic supplementary material The online version of this article (https://doi.org/10.1007/s1078 4-018-9410-4) contains supplementary material, which is available to authorized users.

Thomas Hahn

thomas.hahn@su.se

Extended author information available on the last page of the article 


\section{Introduction}

Global environmental change calls for a new paradigm in international policy making to "explore options for transformations towards sustainability" (Steffen et al. 2015). One of the root causes of our inability to make progress towards sustainability seems to be that we live in a society where groups with different backgrounds-whether in government, civil society, academic disciplines, high-income countries or low-income countries-tend to cast complex problems as polar opposites (Costanza et al. 2010).

The process of negotiation, where the search for mutual exchange is shaped by persuasion and political power, can be almost contrary to the communication patterns of dialogue and transformational learning (Littlejohn and Domenici 2001). A visualization of this is the Chinese finger trap: When you push your fingers into each end of these straw tubes and then try to remove them, the tube diameter shrinks and grabs the fingers firmly. The more you struggle, the more your fingers are trapped. The only way to create enough room to get your fingers back out is to do something counterintuitive: push them deeper into the tube, which only then relaxes its grip (Hayes 2007).

International conflicts are rooted in different economic interests, political views, commitments and mandates that negotiators have from their respective governments. Solving these requires understanding and cooperation. However, on top of these material conflicts, we have observed international negotiations where governments and other actors, similar to getting stuck in the Chinese finger trap, have acted as polar opposites, sometimes even refusing to talk to each other out of mistrust and anger instead of trying to understand what other parties are trying to express.

The format for formal international negotiations on environment and development sometimes prevents negotiators from truly listening to each other and adapt pre-existing positions to realize constructive conflict resolution. This is an obstacle in international negotiations on environment as well as peace and conflict negotiations, impeding cooperation and efficiency (Galluccio 2015). Multi-stakeholder dialogues can represent key innovations in this context to address these obstacles (Bäckstrand 2006).

The purpose of this paper is to analyse to what extent conflict resolution in international environmental negotiations can be facilitated by providing an arena for dialogue where the experiences and perspectives of diverse actors, including marginalized groups, are acknowledged. As a case study we have chosen the Quito Dialogues focusing on a conflicting process within the Convention on Biological Diversity (CBD). The aim of this paper is to assess the effects of the Quito Dialogues on the formal CBD negotiations. Based on the results we discuss what factors of the Quito Dialogues were decisive for the outcomes.

\section{Methodology}

We first review the literature on dialogue in the context of international environment negotiations and how it relates to transformative social learning (Keen et al. 2005). As a case study we use two Multi-Actor Dialogue Seminars (MADS) conducted in Quito, Ecuador, March 2012 and April 2014, respectively (hereafter called the Quito Dialogues), related to negotiations under the CBD.

To assess the effects of the Quito Dialogues on the formal negotiations within the CBD, we use interviews, questionnaire and text analysis. First, we conducted semi-structured in-depth interviews with ten of the participants in January 2013, 3 months after the 11th 
formal Conference of Parties (COP11) in India October 2012. The interview questions were formalized into a questionnaire which was sent in February 2013 to all participants in Quito $1(N=80)$. These results summarize the effects of Quito 1 on COP11 according to the participants' experiences (Appendix 1 in Electronic supplementary material). Third, we trace tangible effects in decision text and documents related to the formal negotiations at CBD-COP10 (2010), CBD-COP11 (2012) and CBD-COP12 (2014), including associated preparatory meetings (Appendix 2 in Electronic supplementary material).

Participants were also asked to evaluate the first Quito Dialogue (Appendix 3 in Electronic supplementary material) which sheds light on what factors of the Quito Dialogues were decisive for the outcomes. The design factors of the Quito Dialogues are listed in Table 1 and generalized as Multi-Actor Dialogue Seminars (MADS). MADS is an approach which has been developed over the last decade based on dialogue theory (see below) as well as experiences of organising and facilitating international dialogues within the two organizations: SwedBio (Tengö and Malmer 2012; Rockström et al. 2013; Pérez and Schultz 2015; Schultz et al. 2016) and What Next Forum (Hällström 2009). ${ }^{1}$

\section{Theory: dialogues as transformative social learning and conflict resolution}

Dialogue is often discussed within the realm of social or collaborative learning as a key aspect for solving disputes concerning ecosystem management (Daniels and Walker 2001; Bäckstrand 2006; Angelstam et al. 2013). The literature on multi-actor dialogue often focuses on relationships as much as outcomes, with the aim to improve relationships "in ways that create new grounds for mutual respect and collaboration" (Saunders 2009: 379). Multi-actor dialogues aim to "enhance mutual learning by generating and evaluating divergent knowledge claims and viewpoints, i.e. problem structuring" (Cuppen et al. 2010: 579).

Sustained over time and rigorously practiced, dialogues may enable re-evaluation and transformation of conflictual relationships (Saunders 2009). Putnam (2004) has described transformation as moments in the conflict process which redefine the nature of the conflict or the relationship among the parties. According to Capra (2007) social learning has been described as a shift away from expert-based teaching, towards transformative learning. This challenges all actors to consider alternative perspectives and their use of information, "making learning a dynamic and potentially transformative process" (Keen et al. 2005: 4). Rather than assuming fixed preferences when negotiating complex issues like environmental degradation, Amartya Sen (1995) has called for "value formation through public discussion" (p. 18). The dialogue literature is also inspired by coaching techniques and positive psychology, e.g. appreciative inquiry, which argues that a "strength-based collaborative

\footnotetext{
1 SwedBio is a Sida financed programme at Stockholm Resilience Centre, acting as a bridging organization with long experience of facilitation of processes such as international dialogues. What Next Forum (http:// whatnext.org/) with its roots in the Dag Hammarskjöld foundation (http://www.daghammarskjold.se/) has long experience of conducting seminars and dialogues. The methodology for the Quito Dialogues also built on lessons learned from processes such as Crucible II that distinguished itself from other research initiatives in the field at its time by its informal, multi-stakeholder, non-consensus consensus modality (i.e. reaching consensus on where consensus as well as disagreements exist, without attempting to force consensus on the issues themselves), and a neutral forum that promoted open discussion between participants with distinct views who would otherwise perhaps never sit at the same table.
} 
Table 1 The MADS approach: 20 decisive factors for planning and implementation

Factor Description

1. Start-up meeting, elaborating on outcome, scope, These are initial activities, which are conducted in an conveners, organizers, participants, donors, etc. inclusive process (see factors below)

2. Steering group with teamwork and flexibility

Regular planning meetings of the steering group during the planning of the seminar; time for evaluation and deliberation/adaptation set aside during the meeting itself; and its follow-up

3. Trust and inclusive planning

Working with appropriate conveners and diverse actors facilitated by respected bridging organization. Legitimacy arises from extensive and early interaction with key actors to capture views, knowledge and create ownership of the process

4. Right timing

5. Appropriate mix of participants

6. Agenda and "roadmap"

7. Exploring convergence and divergence

8. Literature and website

9. Local host with subject-specific insights and capacity to handle practical details

10. Right venue

11. Clear roles

12. Working groups that work

13. Language and interpretation

14. Chatham House Rule and other house rules
A clear and realistic pathway to influence a specific process

Selected from appropriate institutions, in an open, transparent and democratic process of nomination

Outlining the trajectory and logic of the agenda including Dialogue sessions, content, questions and intended outcomes (see Fig. 1) can contribute to an inclusive planning process for the agenda

An agenda that facilitates diverse perspectives and experiences of the issues not seeking or "forcing" consensus but finding points of convergence and divergence, learning from both "positive" and "negative" lessons

Gathering relevant information in a background report, inviting participants to share information and literature before, during and after the event. To facilitate sharing of information, a website for the dialogue seminar is preferred

Strong relations and friendship are vital for building a good work environment, and harnessing the event momentum and outcomes

Beauty and calmness can be very important aspects of functionality, letting participants relax, build trust and focus on the meeting

Facilitators, co-chairs, rapporteurs, steering group, ombudsman, sponsors have different and complementary responsibilities during the seminar

Productive meetings dedicate time to round-table discussions, focusing on questions elaborated beforehand. Working group participation is planned in detail, ensuring mix of affiliations and views. Rapporteurs are decided beforehand, but groups democratically select their chair. Small-group "buzz" discussions can tackle emerging issues

Ensuring that all participants can speak and be heard equally

Participants are free to use the information received from other participants, but not reveal their identity or their affiliation. Other house rules includes to attack issues but not persons, to stay focused on the seminar and turn mobile off, etc., and to create and maintain an open atmosphere 
Table 1 (continued)

\begin{tabular}{|c|c|}
\hline Factor & Description \\
\hline 15. Field trip & $\begin{array}{l}\text { Offers possibilities to experience practical exam- } \\
\text { ples of the issues and policies being discussed, } \\
\text { with informal conversations and new meetings of } \\
\text { individuals }\end{array}$ \\
\hline 16. Cultural and social events & $\begin{array}{l}\text { Creating a welcoming, joyful and relaxed atmos- } \\
\text { phere is important for participants' well-being, an } \\
\text { essential part of an inclusive and participatory event }\end{array}$ \\
\hline 17. Open Space session & $\begin{array}{l}\text { Topics that were not included in the formal pro- } \\
\text { gramme but emerge from discussions can be raised } \\
\text { for group discussion by participants }\end{array}$ \\
\hline 18. Reporting & $\begin{array}{l}\text { Rapporteurs with subject knowledge are identified } \\
\text { beforehand, and report in unbiased ways on discus- } \\
\text { sions and presentations (with input from present- } \\
\text { ers), contributing to event co-chairs' reports and } \\
\text { other outputs }\end{array}$ \\
\hline 19. Outreach planned from the outset & $\begin{array}{l}\text { Dialogue websites allow for dissemination and shar- } \\
\text { ing of information throughout the process. The } \\
\text { places and policy channels where Dialogue reports } \\
\text { are presented need to be clear to all participants }\end{array}$ \\
\hline 20. Evaluation and follow-up & $\begin{array}{l}\text { Post-event questionnaires for feedback are important } \\
\text { for learning, communicating outcomes, planning } \\
\text { follow-up activities and reporting to funders and } \\
\text { sponsors }\end{array}$ \\
\hline
\end{tabular}

inquiry is a pathway to cultivate positive emotional experiences, which can be used to build relational strength" (Sekerka and Fredrickson 2010: 86).

Despite these advances in the social sciences, international negotiations are most often focused on reaching targeted solutions without tapping into the potentials offered by the learning and dialogue frameworks. Emphasizing dialogue in international negotiations would mean a shift from the "realist paradigm" focusing on political power to the "relational paradigm" (Saunders 2009: 377).

Dialogue takes a different approach to talking and listening compared to negotiation, mediation, debate and argument (Saunders 2009). Rather than perpetuating one's own positions under the debate or negotiation mode, the dialogue mode allows people to step back and explore what other parties are actually trying to bring forward (Tannen 1998). Yankelovich (2001) has defined dialogue by three qualities: (1) equality and the absence of coercive influences; (2) listening with empathy; and (3) bringing assumptions into the open.

For contentious issues and with asymmetric power structures among participants, it is important to listen openly without looking for flaws in the argument of others or to immediately present counter-arguments. In this sense, trust building and acceptance of diverging experiences and perspectives can be important steps towards building a common understanding (Johannessen and Hahn 2013). Well-prepared dialogues can contribute to identifying areas of agreement and disagreement, building trust and understanding, and identifying policy solutions that are flexible enough to possibly be tailored to different cultural-political and belief systems (Hahn et al. 2015). 
Dialogue with various stakeholders is believed to generate knowledge, empowerment and a common understanding for implementing policies (Siebenhüner 2004). However, evaluations of stakeholder dialogues and other social learning interventions suggest that there are several factors, including institutions, leadership, facilitation and historical experiences, that together with learning contribute to desired outcomes (Nykvist 2014). Reed et al. (2010) propose the following criteria to assess transformative social learning: change in the understanding of individuals involved; that this change goes beyond the individual and becomes situated within wider social units or communities of practice, and that it occurs through social interactions and processes between actors within a social network.

\section{Case study: the Quito dialogues}

In 2010, the tenth meeting of the Conference of the Parties (COP10) to the CBD resulted in a Strategic Plan with the associated Aichi Biodiversity Targets. The implementation of the Strategic Plan requires resource mobilization, and the CBD has adopted a strategy to enhance international and domestic funding for biodiversity, which include new and innovative financing mechanisms. According to the CBD decision, this could include environmental fiscal reforms (e.g. tax reforms and elimination of harmful subsidies); payments for ecosystem services (PES); biodiversity offsets; markets for green products; biodiversity in climate change funding; and biodiversity in international development finance (CBD-COP 9, Decision 11, 2008).

However, in the last hours of COP10, for the first time in the history of CBD, a whole decision was deleted. It was the decision on innovative financial mechanisms. Parties could not reach agreement because some parties felt that the institutional frameworks and regulations of markets and safeguards were not elaborated enough, while at the same time a lack of trust and an absence of dialogue between stakeholders with different political views prevailed. The conflict concerned issues such as monetary valuation of nature and whether instruments such as PES and biodiversity offsets can, or should, be used to protect biodiversity. The conflict also included the role of the private sector, and not least the role of the financial sector in resource mobilization for biodiversity. Triggered by these dramatic events, an agreement was made by staff at the Sida funded SwedBio (a programme at Stockholm Resilience Centre) and Norad (Norwegian Agency for Development Cooperation) to initiate a dialogue seminar as a possible way to move out of the deadlock well in time for the next COP (2 years later).

\subsection{Legitimacy and the Quito dialogues}

The goal of the Quito 1 dialogue was to provide an informal setting for an open exchange of views among diverse actors, including negotiators (i.e. governmental officials representing their respective countries in CBD negotiations), to understand the different worldviews underlying this conflict and prepare for mutually beneficial decisions at the subsequent official CBD negotiations in India (COP-11), October 2012. The seminar was not intended to draft formal recommendations, but rather seek to clarify areas of convergence and divergence among participants, and by that enhance the understanding of various perspectives on financing for biodiversity, including the role and nature of innovative financial 
mechanisms. In selecting participants the organizers had an explicit aim of bringing into dialogue both converging and diverging views, and exploring the social collaborative learning that could emerge from these interactions in a well-planned, facilitated and respectful environment.

The first step in the dialogue process was to create legitimacy for this vision in the CBD community. The Secretariat of the CBD as well as the governments of Sweden, Norway, Ecuador, India and Japan showed interest and became the formal conveners of the dialogue. IUCN-Sur in Ecuador agreed to be the local host and the convener countries constituted a steering committee. A 4-day-long Dialogue Seminar was then organized in Quito, Ecuador, in March 2012 under the title "Scaling up of Biodiversity Finance." Participants were selected through a nomination process through the normal procedures of the secretariat of CBD. Quito 1 included around 80 participants, ranging from governmental negotiators (over half of the participants) representing about 30 countries. It included the main negotiators regarding the conflict under the CBD on innovative financial mechanisms and members of civil society organizations, academia, indigenous peoples, business and intergovernmental institutions. The agenda was designed to bring up both convergences and divergences, constructed around short presentations, by diverse actors with different experiences and perspectives, including research and both "positive" and "negative" case studies, and mixed with discussions in plenary and in working groups. The dialogue mode was emphasized throughout the seminars, to give space for all participants to talk, discuss, listen and exchange views. Representatives from India and Sweden co-chaired the event and had an ombudsman role.

At COP11 in India, October 2012, 7 months after Quito 1, the EU, supported by countries that, before the first Quito dialogue, raised issues of concern regarding innovative financial mechanisms at COP10, suggested a continuation of the Quito dialogue. Convener governments were expanded to include also the Republic of Korea, Uganda and the European Commission. Quito 2 was organized in April 2014 similarly to Quito 1, but focused more on country-specific experiences.

\subsection{Emerging themes at the Quito dialogues}

Presentations by researchers at the first Quito dialogue clarified the diverse nature of biodiversity financing mechanisms, e.g. that biodiversity offsets (ecological compensation) and payments for ecosystem services (PES) can be designed to fit different cultural and political contexts, not only be regarded as "market-based instruments" (Vatn et al. 2011); (Fletcher and Breitling 2012); Hahn et al. 2015). Earlier, at COP10, this freedom in design was not even discussed, partly due to that EU pushed for concepts like Biodiversity offsets and PES without acknowledging cultural and political settings in other parts of the world.

Quito 1 included presentations on valuation, good governance, rights-based frameworks and safeguards to ensure good social and ecological outcomes, encompassing a diversity of opinions on these issues (Farooqui and Schultz 2012); most of these issues were readdressed and elaborated during Quito 2 (Ogwal and Schultz 2014). See Roadmap of Quito 2 in Fig. 1. 
Dialogue seminar: Scaling up Biodiversity Finance

Quito, 9-12 April 2014

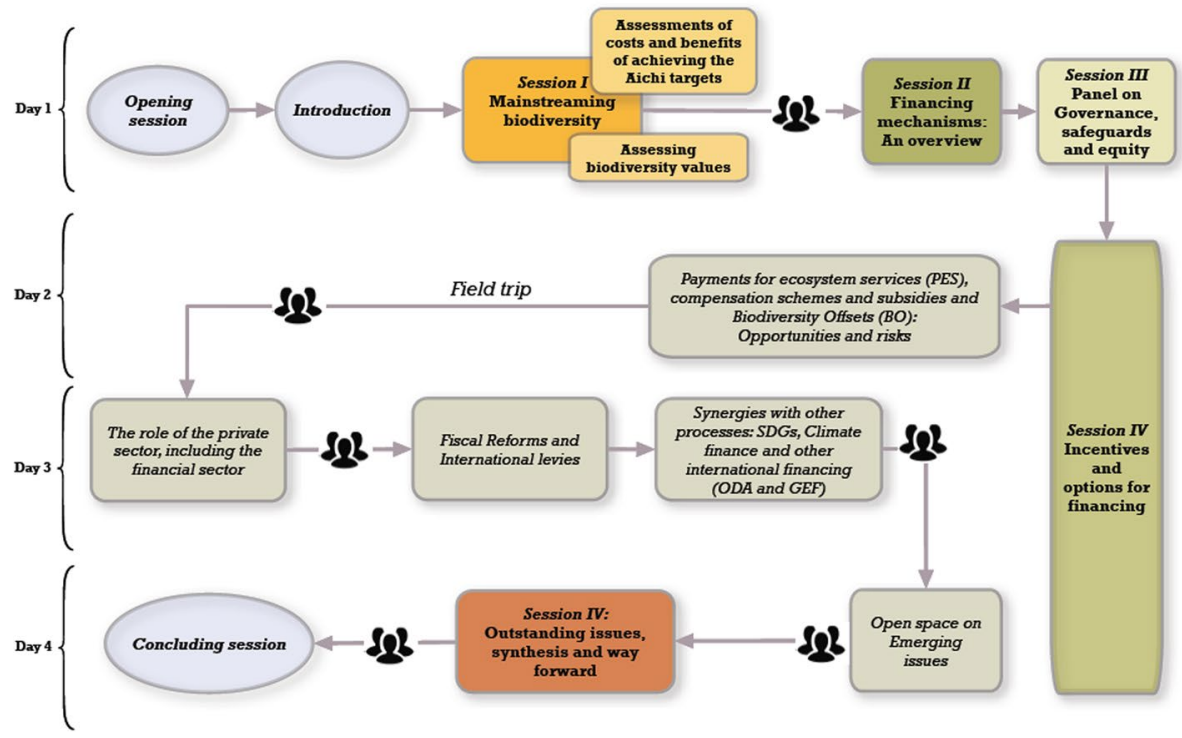

Fig. 1 The Quito 2 "road map" of content and back-casting clarifies and visualizes issues that need to be put on the table and questions needed to be addressed to achieve deeper social learning and understanding. Source: Ogwal and Schultz (2014)

\section{Results}

The outcomes of a social learning process can be evaluated on different scales, e.g. tangible outcomes in related policy areas, and a general increased capacity for conflict resolution and adaptive governance (Plummer and Armitage 2007; Plummer et al. 2012). In this paper, we find that the distinction between tangible and intangible outcomes is useful to assess the outcomes of the Quito Dialogues. Tangible outcomes are evident mainly in formal CBD decision text in Conference of the Parties Decisions and associated formal meetings (Appendix 2 in Electronic supplementary material). Intangible effects, in terms of a general increased capacity for conflict resolution, are evident mainly from the interviews and the answers to the questionnaire (Appendix 1 in Electronic supplementary material). Table 2 summarizes significant tangible and intangible outcomes.

The Quito dialogues (Farooqui and Schultz 2012, Ogwal and Schultz 2014) revealed that part of the conflicts concerned conceptual ambiguity. The terms "innovative financial mechanisms" and "markets" had accommodated different interpretations and made the negotiations unnecessarily difficult. Rather than talking about markets in abstraction, the need was expressed to specify whether one was referring to, for example, local markets with local certified products or, for example, markets relating to "financialization"- the process of turning "biodiversity assets" in new ecosystem services markets into financial products in financial markets. Many participants felt the expression "markets for biodiversity" should be avoided or clarified for each context since it is ambiguous what "markets" imply, from local to global context, and to what extent economic instruments like taxes and payments involve markets. 
At Quito 2 (Ogwal and Schultz 2014) it was reiterated that there is a need for clearer terminology as controversies and disagreements around these issues relate both to language as well as real divergences rooted in different worldviews. As an example, the word compensation is in some contexts used for PES and in some contexts used for offsets; the differences depend on language, politics and institutional design (country context) (Hahn et al. 2015). There were also different sets of concerns around voluntary compared to liability compensation. In particular, pluralism in adapting economic instruments to country-specific concerns, as well as the importance of legal frameworks including social and biodiversity safeguards for any mechanism, was emphasized at Quito 2.

At Quito 2 it was also acknowledged that valuation of biodiversity can be done using a number of methods, from dialogues with relevant actors who communicate and demonstrate qualitative values - to valuation in quantitative and monetary terms, and that valuation does not necessarily involve market instruments (Ogwal and Schultz 2014). It was proposed to change the CBD term "innovative financial mechanisms" (IFM) to "biodiversity financing mechanisms" (BFM) since many of these mechanisms are not new and most countries already apply one or several, see result in CBD decision in Table 2. The nuanced understanding of terminology, assumptions and views, particularly in relation to the role of markets and private sector in biodiversity financing discussed at the Quit dialogues, eased tensions at subsequent CBD negotiations (Table 2).

\section{Discussion}

Multi-Actor Dialogue Seminars (MADS) is an approach based on a comprehensive set of design principles (Table 1). Several of these have strong scientific support, like trust building by bridging organizations (Folke et al. 2005; Hahn et al. 2006) and fostering the listening mode rather than the negotiation mode (Tannen 1998; Yankelovich 2001; Saunders 2009). Handling power asymmetries (Berger 2003; Etty et al. 2013) and putting uncomfortable issues of divergence on the table (Rist et al. 2007; Cuppen et al. 2010) also seem to be key factors for thus type of dialogue.

The focus on transformative learning in combination with negotiations may have longterm outcomes beyond the scope of this particular conflict on biodiversity finance and build capacity for adaptive governance (Plummer and Armitage 2007; Hahn and Nykvist 2017). Our results suggest that transformative social learning has taken place in the Quito Dialogues, according to the three criteria suggested by Reed et al. (2010):

1. Demonstrate that a change in understanding has taken place in the individuals involved The nature of the understanding concerning biodiversity financing evolved, from polarized positions between some negotiators, to a shared understanding that particular BFMs may look different depending on the country-specific conditions and cultural-political orientations. Increased social interactions between participants took place: from certain country negotiators not talking to each other to being able to engage in constructive dialogue and truly listening to each other during and most importantly after the Quito Dialogues, which also affected the formal negotiations (see also Table 2).

2. Demonstrate that this change goes beyond the individual and becomes situated within wider social units or communities of practice The Quito Dialogues are explicitly referenced to in formal CBD-COP Decisions (Table 2). The emphasis on the listening mode 
Table 2 Summary of effects of the Quito Dialogues on the formal CBD process

Examples of Quito Dialogues' outcomes

CBD documents and negotiations where dialogue effects are manifested; results of questionnaire and interviews. For more information see Appendix 1 and 2 in Electronic supplementary material.

1. Dialogues' effects on formal pre-CBD-COP meetings (Working Group on Review of Implementation, WGRI) and CBD Conference of the Parties (COP) meetings, and decisions, adopted by 196 member States
The co-chairs' reports of the Quito Dialogues (Farooqui and Schultz 2012; Ogwal and Schultz 2014) became formal information documents to the pre-COP meetings Working Group on Review of Implementation (WGRI) of the CBD (WGRI4 and WGRI5). A plenary presentation of the first Quito Dialogue outcomes was made at the first hours of WGRI 4; and of the second Quito dialogue at side event in the plenary room at WGRI 5

Dialogue outcomes were presented in side events at CBD COP11 in India (2014), COP12 in South Korea (2016) and COP13 in Mexico (2018)

The decisions from WGRI4 and WGRI5 and also COP11 and COP12 explicitly referred to the Quito Dialogues. For example, Decision XI/4 from COP11 made reference to the Quito Dialogues for the further development of Innovative Financial Mechanisms

Corroboration in documents

Document UNEP/CBD/WG-RI/REC/4/2, 2012. 5. (f) Prepare a synthesis report, taking into account the submissions in response to $\mathrm{X} / 3$ 8(c) as well as other sources of information as appropriate, such as the informal seminar dialogue on Scaling-up Biodiversity Finance held in Quito, Ecuador from 6 to 9 March 2012 ...

The following CBD documents also refer to the Quito dialogues: Document UNEP/CBD/COP/ $\mathrm{DEC} / \mathrm{XI} / 4,2012$. Decisions adopted by the conference of the parties to the CBD at its 11 th meeting, $\mathrm{XI} / 4$. Review of implementation of the strategy for resource mobilization, including the establishment of targets; Document UNEP/CBD/COP/12/4, 2014. WGRI 5 Recommendation 5/10 Review of implementation of the strategy for resource mobilization; Document UNEP/CBD/COP/DEC/XII/3, 2014. Decision adopted by the COP12 of CBD, XII/3. Resource mobilization. 
Table 2 (continued)

Examples of Quito Dialogues' outcomes

CBD documents and negotiations where dialogue effects are manifested; results of questionnaire and interviews. For more information see Appendix 1 and 2 in Electronic supplementary material.

2. Shared understanding of terminology manifested in CBD-COP Decisions
It was recognized in the Quito dialogues that there were a need for clearer terminology as controversies and disagreements around these issues related both to language as well as real divergences based in different worldviews

The new term "biodiversity financing mechanisms" proposed in Quito Dialogues helped to ease tensions concerning "new and innovative financial mechanisms," which had been perceived to push a non-rights-based market-based agenda that some parties were in opposition to

Corroboration in documents:

UNEP/CBD/COP/DEC/XII/3, Decisions adopted by the conference of the parties to the Convention on Biological Diversity (XII/3. Resource mobilization), paragraph:

14. Urges Parties and other Governments to further develop and use various sources of funding, as appropriate, in accordance with national circumstances and conditions, including market and non-market based instruments and biodiversity financing mechanisms; footnote 3 "The term 'biodiversity financing mechanisms' refers to 'new and innovative financial mechanisms' under Goal 4 of the strategy for resource mobilization, adopted by the Conference of the Parties at its ninth meeting (decision IX/11). New and innovative financial mechanisms are supplementary to and do not replace the Financial Mechanism established under the provisions of Article 21 of the Convention (see preamble to decision X/3)."

Dialogue participants' (parties-official negotiator) perspectives on outcomes:

"I think the possibility to articulate market based and rights based approaches has definitely been formulated more explicitly in some decisions of COP11."

"The report that was made for the seminar; "Can markets save biodiversity?" created a common ground and a common understanding of the issue of market based mechanisms, the most contentious part of the innovative financial mechanisms

The dialogue itself clarified the fear that was attached to the use of market based mechanisms, and drew the attention of worry from commodification over to financialisation; of the unknown consequences of leaving the trade on biodiversity to the international financial market that do not have any link/ contact/responsibility to the local level where the biodiversity is." 
Table 2 (continued)

Examples of Quito Dialogues' outcomes

CBD documents and negotiations where dialogue effects are manifested; results of questionnaire and interviews. For more information see Appendix 1 and 2 in Electronic supplementary material.

3. New voluntary guidelines on Safeguards adopted at a CBD-COP Decision emerging from needs expressed in Quito I and building on feedback to proposed guidelines at Quito 2

4. Trust building with positive outcome on the negotiations, e.g. it unlocked a deadlock in the negotiations in pre-CBD-COP meetings and CBD-COPs
Safeguards refer to measures for minimizing negative impacts while maximizing the positive impacts of an intervention, and the needs for safeguards was identified at Quito 1

Corroboration in documents

An Information Document on safeguards and biodiversity financing (Ituarte-Lima et al. 2012) was included in the COP11 documents, responding to needs of safeguards identified at Quito 1

Decision CBD COP11, XI/4, requested the CBD Secretariat to further develop the Information Document on Safeguards with comments and inputs from Parties and relevant stakeholders and requested WGRI5 to prepare a recommendation for the consideration by COP12

The subsequent COP12 later adopted voluntary guidelines (Decision XII/3) based on an elaborated Information Document including proposed guidelines for safeguards in BFMs and suggested operational next steps (Ituarte-Lima et al. 2014)

These proposed guidelines adopt a rights/responsibilities based approach to substantive safeguards (e.g. land, tenure and knowledge-related rights) and procedural safeguards (e.g. participation, transparency and accountability) while recognizing that both are necessary and interdependent

Further negotiations of the implementation of these safeguards took place at COP 13 and onwards

Dialogue participants' (parties-official negotiators) perspectives on outcomes

"It eased the tension that complicated the negotiations at COP 10 in Nagoya."

"The seminar helped to listen to each other's views and overcome blockages, which a part from differing political positions often also result from the lack of communication during stressful negotiation settings." "Strengths:... Room for discussions and trust building"

"Quito I was tremendously useful for confidence building, it created a climate of confidence, some countries rethought the position on IFMs because they were more informed about the different aspects after Quito, main achievement was the climate on trust;"’ 
Table 2 (continued)

Examples of Quito Dialogues' outcomes

CBD documents and negotiations where dialogue effects are manifested; results of questionnaire and interviews. For more information see Appendix 1 and 2 in Electronic supplementary material.

5. Effects of dialogues on social learning and conflict resolution, Reed et al. (2010); Plummer and Armitage (2007: 71), and Dowd (2015)

\section{Corroboration in documents \\ Conflict resolution have been manifested in CBD negotiations and COP Decisions, explicitly refer- ring to Quito dialogues (point 1 above), written interpretation of key terms (point 2 above) and guidelines for safeguards (point 3 above) \\ Dialogue participants' perspectives on effects \\ "The conclusions, results and opinions of the seminar have been used at the COP 11 and other negotiation's spaces. The concepts and the different discussions have generated new global visions for innovative mechanisms"(Official negotiator) \\ "The two Quito dialogues have shown a richness of ideas, and that coming CBD meetings would be arranged to include dialogues between negotiators for effective outcomes" (Executive Secretary of CBD, Dr. Braulio Dias)}

and putting all issues of divergence on the table but avoid drafting formal recommendations-was probably decisive for reaching convergence at the formal CBD negotiations.

3. Occur through social interactions and processes between actors within a social network In this case the Quito Dialogues provided a facilitated meeting space for diverse actors, such as those who are generally marginalized in decision-making at the global and subnational levels (e.g. indigenous peoples and local communities) as well as governments from distinct geographical spaces, cultural, economic and political contexts. The Quito dialogues made the linkages between knowledge and power more transparent and enabled the co-development of knowledge and understanding of convergence and divergence, without forcing convergence, which is important in conflict resolution (Yankelovich 2001).

As described by Yankelovich (2001), it is important to be aware if and when an informal dialogue seminar is transitioning to a more formal negotiation mode. Our findings suggest that a dialogue may enrich a formal negotiation; however, a dialogue should be kept distinctly separate in time from formal negotiations. Otherwise, there is a risk that participants start drafting recommendations and the listening mode is replaced by expectations to achieve results according to their own countries' or organizations' instructions and motivations.

Dialogue seminars can be a constructive way to handle power asymmetries. By inviting a truly wide range of participants to a dialogue seminar and including their wide-ranging and often conflicting experiences and perspectives in the programme, both as formal presentations and in round-table discussions, actors that are normally marginalized get a voice. By treating all participants as "experts" and equals, existing power relations are indeed challenged. This can, however, be tricky to achieve because some groups may for historical 
reasons be suspicious and question that the dialogue is balanced or fair enough. For example, one civil society organization which expected that the first Quito Dialogue would be biased towards markets was asked to write a letter, which described the perceived risk of market instruments, which was read in plenary by a like-minded organization at the opening of Quito 1.

Power asymmetries among different groups often hinder sustainable environmental outcomes (Berger 2003; Etty et al. 2013). In contrast to a politically neutral discourse on resource management, social learning through dialogue makes explicit the often tacit conceptions behind the values, norms and rules in highly heterogenic actor groups and the power relationships derived from them (Rist et al. 2007). Participation of distinct actor groups in a dialogue may facilitate deliberation to redefine norms, rules and power relationships to overcome conflicts and foster sustainability.

Dialogues may become a hollow pretext for inclusion and participants might feel hijacked and manipulated unless they feel there have been genuine attempts of inclusive process and to challenging governance and power relations. A real dialogue has only taken place if diverse actors and participants acknowledge that there has been a dialogue-afterwards. The Quito Dialogues were part of a larger governance process, and the goal and expectations were clear and transparent to all participants; power structures were addressed constructively by showing that the views of marginalized actors were part of a larger discussion on the value of nature, both in academic terms and beyond (Hahn et al. 2015; Vatn 2015).

Engaging diverse academic, practitioner and negotiator perspectives contributed to further understanding and addressing divergences. These dynamics also allowed overcoming the framing of the conflicts as only between some countries with opposite political ideas about markets and it contributed to understanding distinct academic and empirical arguments for and against various BFMs as challenges, e.g. to what extent and under what conditions "markets" can protect biodiversity (Vatn et al. 2011). The dialogues deepened and offered more nuanced understandings of different assumptions and views, particularly in relation to the role of the markets and private sector in biodiversity financing.

Quito 1 entailed one and a half years of detailed and participatory planning and preparation, which was required to gain support and legitimacy from a range of actors. A bridging organization can provide "an arena for trust-building, vertical and horizontal collaboration, learning, sense-making, identification of common interests, and conflict resolution" (Hahn et al. 2006). A bridging organization could be a research institute, an environmental NGO or a governmental organization and the collaboration could be formalized or very informal, bottom-up or top-down (Folke et al. 2005). In this case study, SwedBio could act as a bridging organization who had gained legitimacy, through their long-term engagement as facilitator of processes in relation to the CBD negotiations, from a diversity of actors, including governments and civil society organizations.

Another key factor for the outcome was the collaboration with the CBD secretariat, which has the mandate to bring together actors through an inclusive transparent nomination process, and which brought main negotiators to the dialogues. Legitimacy was further enhanced by a collaborative and adaptive setting in terms of planning, so that many actors felt ownership of the process, which are key aspects of stakeholder interaction according to Plummer and Armitage (2007).

The Quito Dialogues focused on the global scale, i.e. the negotiations under the CBD, but would not have been as effective without examples and lessons learned from the national and local scales. Addressing policy issues at the global level can create legitimacy, and foster laws and institutions that are adaptable and equitable (Young 2003) and 
can frame and promote policy development at regional and national levels (Malayang et al. 2006). International environmental law can positively influence national governance systems to achieve socio-ecological goals (Craig 2013; Ebbesson and Hey 2013). But without a good understanding at the global level, of the divergent national and local contexts, global frameworks may become inflexible prescriptive blueprints difficult for many countries to adopt Berkes 2002).

\section{Conclusions}

Dialogues can bring more nuances to understanding the landscape of ideas, values, assumptions, interests and power relationships and contribute to national and international environmental governance. The Multi-Actor Dialogue Seminars (MADS) approach employed in our case study and analysed in this article has built on diverse social learning literature, in particular perspectives viewing social learning as a means for personal, relational and systemic transformation for enhanced environmental governance. The Quito Dialogues were characterized by an inclusive planning process, fostering a listening mode, putting ideologically contested issues on the table and handling power asymmetries to facilitate that the experiences and perspectives of diverse actors, including marginalized groups, are acknowledged. Our results suggest that the Quito Dialogues contributed to transformative social learning, constructive conflict resolution and improved international negotiations in the context of the Convention on Biological Diversity.

In international conflict resolution, there is a need to include understanding of the negotiators' culture, their religion, their native language and the epistemologies (way of knowing) and cognitive heuristics (cognitive rules) they use (Dowd 2015). To help build a shared vision for how to achieve decision-making and implement international commitments, such as related to CBD, and likewise in the broader context the Sustainable Development Goals, we need better dialogue and learning across cultures, interests and various actor groups (Rockström and Schultz 2011). Real dialogues require time and resources, but we see no better alternatives. Improved dialogue cultures may be the biggest single opportunity we have to reach genuine solutions in the quest for a sustainable future.

Acknowledgements The work with this article is inspired by collaborative learning with: the team members in the Sida financed SwedBio programme Pamela Cordero Hernandez, Sara Elfstrand, Ellika Hermansson Török, Pernilla Malmer, Hanna Wetterstrand and other colleagues at Stockholm Resilience Centre such as Sarah Cornell and Maria Tengö; Bente Herstad, Norad and Tone Solhaug, Ministry of Climate and Environment from Norway; Ravi Sharma and his colleagues at the Secretariat of the Convention on Biological Diversity; co-chairs of the Quito seminars M.F. Farooqui, at the time of the Quito I dialogue Additional Secretary, Ministry of Environment and Forests, India, and Sabino Francis Ogwal from National Environment Management Authority, Uganda; Alfonso Wilson Rojas and colleagues at Ministerio del Ambiente; Arturo Mora from IUCN-Sur, and many others not mentioned here, among them partners to SwedBio. The work builds on the long-ranging experience of dialogue seminars across a broad range of issues through What Next Forum and earlier work by the Dag Hammarskjöld Foundation. The dialogues and development of MADS were financed by SwedBio on Sida Grants and by Norad and Japan, and the time spent on this paper was financed by Stockholm Resilience Centre, through a core Grant from Mistra and partly by the Swedish Research Council Formas through the research project "Effective and Equitable Institutional Arrangements for Financing and Safeguarding Biodiversity 254-2013-130."

Open Access This article is distributed under the terms of the Creative Commons Attribution 4.0 International License (http://creativecommons.org/licenses/by/4.0/), which permits unrestricted use, distribution, and reproduction in any medium, provided you give appropriate credit to the original author(s) and the source, provide a link to the Creative Commons license, and indicate if changes were made. 


\section{References}

Angelstam, P., Grodzynskyi, M., Andersson, K., Axelsson, R., Elbakidze, M., Khoroshev, A., et al. (2013). Measurement, collaborative learning and research for sustainable use of ecosystem services: Landscape concepts and Europe as laboratory. Ambio, 42(2), 129-145.

Bäckstrand, K. (2006). Democratizing global environmental governance? Stakeholder democracy after the world summit on sustainable development. European Journal of International Relations, 124, 467498. https://doi.org/10.1177/1354066106069321.

Berger, G. (2003). Reflections on governance: Power relations and policy making in regional sustainable development. Journal of Environmental Policy \& Planning, 53, 219-234.

Berkes, F. (2002). Cross-scale institutional linkages: Perspectives from the bottom up. In E. Ostrom, et al. (Eds.), The drama of the commons (pp. 293-321). Washington, DC: National Academy Press.

Capra, F. (2007). Foreword. In A. E. J. Wals (Ed.), Social learning towards a sustainable world: Principles, perspectives, and praxis. Wageningen: Wageningen Academic Pub.

Costanza, R., Batker, D., Day, J. W., Feagin, R. A., Martinez, M. L., \& Roman, J. (2010). The perfect spill: Solutions for averting the next deepwater horizon. Solutions, 15, 17-20.

Craig, R. K. (2013). Learning to think about complex environmental systems in environmental and natural resource law and scholarship: A twenty-year retrospective. Fordham Environmental Law Review, 24, 87-102.

Cuppen, E., Breukers, S., Hisschemöller, M., \& Bergsma, E. (2010). Q methodology to select participants for a stakeholder dialogue on energy options from biomass in the Netherlands. Ecological Economics, 693, 579-591. https://doi.org/10.1016/j.ecolecon.2009.09.005.

Daniels, S. E., \& Walker, G. B. (2001). Working through environmental conflict-The collaborative learning approach. Westport/London: Praeger.

Dowd, E. T. (2015). Tacit knowledge awareness and its role in improving the decision-making process in international negotiations. In Handbook of international negotiation (pp. 15-25). Cham: Springer. http://doi.org/10.1007/978-3-319-10687-8_2.

Ebbesson, J., \& Hey, E. (2013). Introduction: Where in law is social-ecological resilience. Ecology and Society, 1825, 1-25.

Etty, T., Heyvaert, V., Carlarne, C., Farber, D., Lin, J., \& Scott, J. (2013). Norms, networks, and markets: Navigating new frontiers in transnational environmental law. Transnational Environmental Law, 202, 203-210.

Farooqui, M. F., \& Schultz, M. (2012). Co-chairs' summary of dialogue seminar on scaling up biodiversity finance, Quito 6-9 March 2012, UNEP/CBD/WG-RI/4/INF/9. Montreal.

Fletcher, R., \& Breitling, J. (2012). Market mechanism or subsidy in disguise? Governing payment for environmental services in Costa Rica. Geoforum, 43, 402-411.

Folke, C., Hahn, T., Olsson, P., \& Norberg, J. (2005). Adaptive governance of social-ecological systems. Annual Review of Environment and Resources, 301, 441-473. https://doi.org/10.1146/annurev.energ y.30.050504.144511.

Galluccio, M. (Ed.). (2015). Handbook of international negotiation. Cham: Springer. https://doi. org/10.1007/978-3-319-10687-8.

Hahn, T., McDermott, C., Ituarte-Lima, C., Schultz, M., Green, T., \& Tuvendal, M. (2015). Purposes and degrees of commodification: Economic instruments for biodiversity and ecosystem services need not rely on markets or monetary valuation. Ecosystem Services, 16, 74-82.

Hahn, T., \& Nykvist, B. (2017). Are adaptations self-organized, autonomous and harmonious? Assessing the social-ecological resilience literature. Ecology and Society, 22(1), 12.

Hahn, T., Olsson, P., Folke, C., \& Johansson, K. (2006). Trust-building, knowledge generation and organizational innovations: The role of a bridging organization for adaptive comanagement of a wetland landscape around Kristianstad, Sweden. Human Ecology, 344, 573-592. https://doi.org/10.1007/s1074 5-006-9035-Z.

Hällström, N. (2009), What next-Volume II. In The case for pluralism. The Dag Hammarskjöld Centre. http://www.whatnext.org/resources/Publications/Volume-II/What-Next-Volume-II_full-WN-cover.pdf. Accessed 31 Dec 2016.

Hayes, S. C. (2007). Hello darkness: Discovering our values by confronting our fears. Psychotherapy Networker, 315, 46-52.

Ituarte-Lima, C., Schultz, M., Hahn, T., \& Cornell, S. (2012). Safeguards for scaling-up biodiversity financing and possible guiding principles. In Information document for the CBD-conference of the parties, $U N E P / C B D / C O P / 11 / I N F / 7$. Stockholm Resilience Centre, Stockholm University.

Ituarte-Lima, C., Schultz, M., Hahn, T., McDermott, C., \& Cornell, S. (2014). Biodiversity financing and safeguards: Lessons learned and proposed guidelines. In Information document UNEP/CBD/COP/12/ 
INF/27 for the 12th conference of the parties of the convention on biological diversity in Pyeongchang Korea. Stockholm: SwedBio, Stockholm Resilience Centre at Stockholm University.

Johannessen, Å., \& Hahn, T. (2013). Social learning towards a more adaptive paradigm? Reducing flood risk in Kristianstad municipality, Sweden. Global Environmental Change, 231, 372-381.

Keen, M., Brown, V. A., \& Dyball, R. (2005). In M. Keen, V. A. Brown, \& R. Dyball (Eds.), Social learning: A new approach to environmental management. London: Earthscan.

Littlejohn, S. W., \& Domenici, K. (2001). Engaging communication in conflict: Systemic practice. Thousand Oaks: SAGE. https://doi.org/10.4135/9781452225654.

Malayang III, B. S., Hahn, T., \& Kumar, P. (2006). Responses to ecosystem change and to their impacts on human well-being. In D. Capistrano, et al. (Eds.), Ecosystems and human well-being: Multiscale assessments: Findings of the sub-global assessments working group of the millennium ecosystem assessment (pp. 203-226). Washington, DC: Island Press. http://www.millenniumassessment.org/ documents/document.347.aspx.pdf.

Nykvist, B. (2014). Does social learning lead to better natural resource management? A case study of the modern farming community of practice in Sweden. Society \& Natural Resources, 274, 436-450. https ://doi.org/10.1080/08941920.2013.861562.

Ogwal, S. F., \& Schultz, M. (2014). Co-chairs' summary of second dialogue seminar on scaling up finance for biodiversity, Quito 9-12 April 2014. Montreal.

Pérez, E. S., \& Schultz, M. (2015). Co-chairs' summary dialogue workshop on assessment of collective action in biodiversity conservation, Panajachel, Guatemala-11-13 June 2015. Montreal.

Plummer, R., \& Armitage, D. (2007). A resilience-based framework for evaluating adaptive co-management: Linking ecology, economics and society in a complex world. Ecological Economics, 611, 62-74.

Plummer, R., Crona, B., Armitage, D. R., Olsson, P., Tengö, M., \& Yudina, O. (2012). Adaptive comanagement: A systematic review and analysis. Ecology and Society, 173, 11.

Putnam, L. L. (2004). Transformations and critical moments in negotiations. Negotiation Journal, 202, 275-295. https://doi.org/10.1111/j.1571-9979.2004.00023.x.

Reed, M., Evely, A. C., Cundill, G., Fazey, I. R. A., Glass, J., Laing, A et al. (2010). What is social learning? Ecology and Society, 15(4). http://www.ecologyandsociety.org/vol15/iss4/resp1/.

Rist, S., Chidambaranathan, M., Escobar, C., Wiesmann, U., \& Zimmermann, A. (2007). Moving from sustainable management to sustainable governance of natural resources: The role of social learning processes in rural India, Bolivia and Mali. Journal of Rural Studies, 231, $23-37$.

Rockström, J., Baptiste, B., Cornell, S., Wetterstrand, H., \& Hermansson Török, E. (2013). Integrating social-ecological resilience into the new development agenda. Multi-stakeholder dialogue. In $\mathrm{Co}$ chairs' report. Medellín.

Rockström, J., \& Schultz, M. (2011). Contributing to resilience. In A. Djoghlaf \& F. Dodds (Eds.), Biodiversity and ecosystem insecurity: A planet in peril (pp. 27-36). London: Earthscan.

Saunders, H. H. (2009). Dialogue as a process for transforming relationships. In J. Bercovitch, V. Kremenyuk, \& I. W. Zartman (Eds.), The SAGE handbook of conflict resolution (pp. 376-391). London: SAGE.

Schultz, M., Hahn, T., Hällström, N., \& Ituarte-Lima, C. (2016). The biggest single opportunity we have is dialogue-Dialogue seminars as a methodology for transformative social learning and conflict resolution in international environment negotiations. Stockholm: SwedBio at Stockholm Resilience Centre.

Sekerka, L. E., \& Fredrickson, B. L. (2010). Working positively toward transformative cooperation. In P. A. Linley, S. Harringtodn, \& N. Garcea (Eds.), Oxford handbook of positive psychology and work (pp. 81-94). Oxford: Oxford University Press.

Sen, A. (1995). Rationality and social choice. The American Economic Review, 85, 1-24.

Siebenhüner, B. (2004). Social learning and sustainability science: Which role can stakeholder participation play? International Journal of Sustainable Development, 72, 146-163. https://doi.org/10.1504/ IJSD.2004.005368.

Steffen, W., Richardson, K., Rockström, J., Cornell, S. E., Fetzer, I., Bennett, E. M., et al. (2015). Planetary boundaries: Guiding human development on a changing planet. Science, 347, 1259855.

Tannen, D. (1998). The argument culture: Moving from debate to dialogue. New York: Random House Publishing Group.

Tengö, M., \& Malmer, P. (2012). Dialogue workshop on knowledge for the 21 century: Indigenous knowledge, traditional knowledge, science and connecting diverse knowledge systems. In Workshop report. Guna Yala: Stockholm Resilience Centre

Vatn, A. (2015). Markets in environmental governance. From theory to practice. Ecological Economics, $117,225-233$.

Vatn, A., Barton, D. N., Lindhjem, H., Movik, S., Ring, I., \& Santos, R. (2011). Can markets protect biodiversity? In An evaluation of different financial mechanisms, Noragric report (Vol. 60). 
Yankelovich, D. (2001). The magic of dialogue: Transforming conflict into cooperation. New York: Simon and Schuster.

Young, O. R. (2003). Environmental governance: The role of institutions in causing and confronting environmental problems. International Environmental Agreements, 34, 377-393.

\section{Affiliations}

\section{Maria Schultz $^{1}$ (D) . Thomas Hahn ${ }^{1}$ (ID $\cdot$ Claudia Ituarte-Lima $^{1}$ (D) $\cdot$ Niclas Hällström $^{2}$}

Maria Schultz

maria.schultz@su.se

Claudia Ituarte-Lima

claudia.ituarte@su.se

Niclas Hällström

niclas.hallstrom@whatnext.org

1 SwedBio at the Stockholm Resilience Centre, Stockholm University, 10691 Stockholm, Sweden

2 What Next Forum, Uppsala, Sweden 